\title{
Nanotoxicity: a key obstacle to clinical translation of siRNA-based nanomedicine
}

siRNAs have immense therapeutic potential for the treatment of various gene-related diseases ranging from cancer, viral infections and neuropathy to autoimmune diseases. However, their bench-to-bedside translation in recent years has faced several challenges, with inefficient siRNA delivery being one of the most frequently encountered issues. In order to improve the siRNA delivery especially for systemic treatment, nanocarriers made of polymers, lipids or inorganic materials have become almost essential. The 'negative' aspects of these carriers such as their nanotoxicity and immunogenicity thus can no longer be overlooked. In this article, we will extensively review the nanotoxicity of siRNA carriers. The strategies for mitigating the risks of nanotoxicity and the methodology for evaluating these strategies will also be discussed. By addressing this often overlooked but important issue, it will help clear the way for siRNAs to fulfill their promise as a versatile class of therapeutic agents.

\section{KEYWORDS: cationic lipid clinical trial delivery nanocarrier nanoparticle nanotoxicity polymer RNAi siRNA toxicological evaluation}

siRNA is a short (typically 20-27 bp) dsRNA molecule that can be endogenously found in a cell or introduced from exogenous sources (e.g., synthetic siRNAs) by transfection. siRNAs are particularly known for their ability to silence gene expression via RNAi in a sequencespecific and potent manner (nanomolar range) $[1,2]$. Under this mechanism, one strand of the siRNA molecule in the cytoplasm serves as a template to recognize a complementary sequence in mRNA. The resulting interaction induces mRNA degradation and downregulation of the corresponding protein. In addition, siRNAs are also involved in other activities such as antiviral mechanisms and chromatin structure shaping $[3,4]$. In comparison with DNA plasmids and antisense oligonucleotides, synthetic siRNAs are easier to construct, customize and modify [5]. They, therefore, quickly became an indispensable experimental tool for gene function validation [5], and the discoverers of the RNAi mechanism and dsRNA tools were quickly awarded the 2006 Nobel Prize in Physiology and Medicine.

It is stated on the Nobel Prize website that the discovery of RNAi "will most likely lead to novel medical applications in the future" [201]. With the ability to inhibit a selected pathogenic molecular pathway at ease, there has been much hope for the clinical application of siRNAs in various gene-related diseases [6] ranging from cancer [7], viral infections [4] and neuropathy [8] to autoimmune diseases $[9,10]$. Their ease of customization and strong versatility also hint at the potential of personalized medicine [11]. Extensive studies to explore the therapeutic potential of siRNAs have been conducted in the past decade [6] and promising in vitro and in vivo efficacy findings were obtained. The clinical translation of siRNA therapeutics, however, has turned out to be more challenging, with inefficient siRNA delivery and the issues associated with the siRNA delivery vehicles being the key problems [6,7].

Numerous nanocarrier systems have been developed to improve siRNA delivery (see reviews by Zhao et al. and Kesharwani et al. $[12,13])$. In this review, our focus is on the toxicity of these nanocarriers. The strategies for mitigating the risks of nanotoxicity and the methodology for evaluating these strategies will also be discussed. It should be noted that even though certain siRNA therapeutics are designed with the intent to be 'toxic' to specific target cells (e.g., anticancer effects in cancer treatment), one should distinguish between their efficacy (intended effects) and toxicity (undesirable effects). These siRNA therapeutics should be cytotoxic only to the target cells/tissues and have minimal effects on the nontarget ones (e.g., normal tissues in cancer treatment). If the nanocarrier's cytotoxic effects are less specific they should be considered a form of toxicity. One should also distinguish the cytotoxic effects from the siRNA and those from the nanocarrier. Even for a cytotoxic siRNA therapy, it is often more desirable if the cytotoxicity is caused by
Hui Yi Xue ${ }^{1}$, Shimeng Liu ${ }^{1}$ \& Ho Lun Wong*1 ${ }^{1}$ School of Pharmacy, Temple 'School of Pharmacy, Temple
University, 3307 North Broad Street, Philadelphia, PA 19140, USA *Author for correspondence: Tel.: +1 2157078173 Fax: +12157073678 ho-lun.wong@temple.edu 
the RNAi effects of the siRNA, not by the toxic effects of the nanocarrier. As will be discussed, the toxicity of nanomaterials is often less target specific and more complex and unpredictable, and thus should be kept at a minimum level. It is our hope that this review will help nanomedicine researchers and clinicians to be more aware of these carrier toxicity issues so safer therapeutic siRNA products with higher translational success can be developed.

\section{Clinical translation of siRNA therapeutics \& the need for nanocarriers}

TABLES $1 \& 2$ summarize the major clinical trials of siRNA therapeutics (local therapy [T Table 1$]$ and systemic therapy [Table 2]). The first clinical trial of siRNA began in 2004 (Table 1). This Phase I study indicated that Cand5 siRNA (i.e., bevasiranib) used for local intravitreal treatment of aged-related macular degeneration was well tolerated [14]. Since then more siRNA trials have been conducted [5]. With a few exceptions, these trials were limited to Phase I and early Phase II stages. Several of the trials were on similar siRNA drugs for similar disease conditions. For example, 11 trials (TABLE 1) including three siRNA drugs were for aged-related macular degeneration and diabetic macular edema; and ALN-VSP and TKM-PLK1 were both for liver cancer. Approximately half of the trials involved the less demanding local therapy. Given the immense therapeutic potential of siRNA-based drugs, the efficiency of their clinical translation clearly has room to improve.

The observed inefficiency is associated with two major categories of issues. First, the nonspecific effects of siRNA, such as off-target effects [15], and a tendency to trigger innate immune response via Toll-like receptor activation [16]. Second, siRNA delivery issues derived from the inherent limitations of naked siRNA, which include inefficient cell permeation due to their size (13-14 kDa), hydrophilicity and polyanionic nature, poor stability in circulation and unfavorable distribution to nontarget cell types [7]. Careful siRNA construction, modification and screening can often effectively solve the first category's issues but not the delivery problems. In a study using naked backbone-stabilized antiHBV-siRNAs in a murine model [17], intravenous dosing of $30 \mathrm{mg} / \mathrm{kg}$ three-times daily was required to be effective. This translates into an overwhelming $6 \mathrm{~g} /$ day dose for an average $70 \mathrm{~kg}$ adult human. The delivery issues may not be obvious in the local therapy trials (e.g., by intravitreal administration in bevasiranib trials, by ophthalmic drops in SYL040012 trials [202], nasal sprays in ALN-RSV01 trials [203]), but must be addressed for systemic siRNA applications.

Besides using siRNA conjugates [18,19], the most common approach to improve siRNA delivery is the use of nanocarriers [12,13]. TABLE 2 shows that all 15 trials for systemic treatment involved a nanocarrier, most notably the lipid nanoparticle (LNP) system (formerly named stabilized nucleic acid lipid particles) [20,204]. Considering that it is a common practice to use nanocarriers, it is impossible to overlook their toxicity when designing a systemic siRNA therapy.

\section{Nanotoxicity of siRNA carriers: a general overview \\ - General factors that modify nanotoxicity}

Once downsized to nanoscale, many normally 'inert' materials can become substantially more reactive probably owing to the dramatic increase in total surface area. This results in more extensive interactions between these materials and the biological systems, causing damage to human body at the organ, tissue and cell levels, and the manifestation of 'nanotoxicity' [21]. siRNA nanocarriers deserve particular attention owing to their complexity and frequent inclusion of toxic cationic materials that tend to interact well with various biological components [12]. The transient nature of their RNAi activity (3 days to 1 week) also implies that frequent, repeated administration will be required for chronic diseases, and the risk of cumulative toxicity is expected to increased [22].

Nanotoxicity can be accentuated by many factors (Table 3). Our early understanding of these factors mostly came from findings related to environmental exposure to inorganic or simple organic particulate matters [21]. For instance, the slim shape of an asbestos fiber allows this material to physically interfere with the chromosomes, disrupting normal cell activities, such as mitosis [23]. Studies on carbon and titanium oxide particles indicated that the smaller their size the higher is the pulmonary toxicity they cause is [24]. Schaeublin et al.'s study with gold nanoparticles showed that surface charge was also a key determinant of their toxic effects on cellular processes [25]. Neutral nanoparticles caused cell death through necrosis in $\mathrm{HaCaT}$ cells, whereas charged nanoparticles induced apoptotic cell death. Other factors such as nanocarrier ingredients, dose level and duration of exposure, and routes of exposure may also affect the toxicity of a nanocarrier $[21,26,27]$. 


\section{Table 1. Clinical trials of locally delivered siRNA therapeutics.}

\begin{tabular}{|c|c|c|c|c|c|c|c|}
\hline SIRNA & Carrier & $\begin{array}{l}\text { Administration } \\
\text { route }\end{array}$ & $\begin{array}{l}\text { Year } \\
\text { started }\end{array}$ & Phase & Disease & Notes & $\begin{array}{l}\text { ClinicalTrials.gov } \\
\text { identifier }\end{array}$ \\
\hline \multirow[t]{5}{*}{$\begin{array}{l}\text { Bevasiranib } \\
\text { (Cand5) }\end{array}$} & \multirow[t]{5}{*}{ NC } & \multirow[t]{5}{*}{ Intravitreal } & 2004 & I & AMD & $\begin{array}{l}\text { First RNAi clinical } \\
\text { trial }\end{array}$ & NCT00722384 \\
\hline & & & 2005 & $\|$ & AMD & & NCT00259753 \\
\hline & & & 2006 & $\|$ & DME & & NCT00306904 \\
\hline & & & 2007 & III & AMD & $\begin{array}{l}\text { Terminated due to } \\
\text { lack of efficacy }\end{array}$ & NCT00499590 \\
\hline & & & 2009 & III & AMD & Withdrawn & NCT00557791 \\
\hline \multirow{2}{*}{$\begin{array}{l}\text { Sirna-027 } \\
\text { (AGN211745) }\end{array}$} & \multirow[t]{2}{*}{ NC } & \multirow[t]{2}{*}{ Intravitreal } & 2004 & I & \multirow[t]{2}{*}{ AMD } & & NCT00363714 \\
\hline & & & 2007 & $\|$ & & $\begin{array}{l}\text { Terminated due to } \\
\text { lack of efficacy }\end{array}$ & NCT00395057 \\
\hline \multirow{4}{*}{$\begin{array}{l}\text { PF-04523655 } \\
\text { (REDD14NP, } \\
\text { RTP801I-14) }\end{array}$} & \multirow[t]{4}{*}{ NC } & \multirow[t]{4}{*}{ Intravitreal } & 2007 & I & AMD & & NCT00725686 \\
\hline & & & 2008 & $\|$ & DME & $\begin{array}{l}\text { Terminated due to } \\
\text { lack of efficacy }\end{array}$ & NCT00701181 \\
\hline & & & 2009 & II & AMD & & NCT00713518 \\
\hline & & & $2012^{+}$ & $\|$ & DME & & NCT01445899 \\
\hline \multirow[t]{3}{*}{ QPI-1002 (I5NP) } & \multirow[t]{3}{*}{ NC } & \multirow[t]{3}{*}{ iv. injection } & 2007 & I & \multirow{2}{*}{$\begin{array}{l}\text { Acute kidney injury post } \\
\text { cardiac surgery }\end{array}$} & & NCT00554359 \\
\hline & & & 2008 & I & & $\begin{array}{l}\text { Terminated due to } \\
\text { lack of participants }\end{array}$ & NCT00683553 \\
\hline & & & $2008^{+}$ & $|/| \mid$ & $\begin{array}{l}\text { Delayed graft function } \\
\text { post kidney transplant }\end{array}$ & & NCT00802347 \\
\hline QPI-1007 & NC & Intravitreal & 2010 & I & $\begin{array}{l}\text { Optic nerve atrophy, } \\
\text { NAION }\end{array}$ & & NCT01064505 \\
\hline \multirow[t]{3}{*}{ ALN-RSV } & \multirow[t]{3}{*}{ NC } & Intranasal & 2007 & $\|$ & RSV infection & & NCT00496821 \\
\hline & & \multirow[t]{2}{*}{ Nebulization } & 2008 & II & \multirow{2}{*}{$\begin{array}{l}\text { RSV infection in lung } \\
\text { transplant patients }\end{array}$} & & NCT00658086 \\
\hline & & & 2010 & $\|$ & & & NCT01065935 \\
\hline TD101 & NC & Local injection & 2008 & I & Pachyonychia congenita & 1 patient & NCT00716014 \\
\hline \multirow[t]{3}{*}{ SYL040012 } & \multirow[t]{3}{*}{ NC } & \multirow[t]{3}{*}{ Ophthalmic drop } & 2009 & I & \multirow{3}{*}{$\begin{array}{l}\text { Ocular hypertension, } \\
\text { glaucoma }\end{array}$} & & NCT00990743 \\
\hline & & & 2010 & $|/ I|$ & & & NCT01227291 \\
\hline & & & 2012 & $\|$ & & & NCT01739244 \\
\hline \multirow[t]{2}{*}{ SYL1001 } & \multirow[t]{2}{*}{ NC } & \multirow[t]{2}{*}{ Ophthalmic drop } & 2011 & I & \multirow{2}{*}{$\begin{array}{l}\text { Ocular pain, dry eye } \\
\text { syndrome }\end{array}$} & & NCT01438281 \\
\hline & & & $2012^{\dagger}$ & $|/ I|$ & & & NCT01776658 \\
\hline \multirow[t]{2}{*}{ siG12D } & \multirow[t]{2}{*}{ LODER $^{\circledR}$} & \multirow{2}{*}{$\begin{array}{l}\text { Implantation in } \\
\text { tumor }\end{array}$} & $2011^{\dagger}$ & I & Pancreatic cancer & & NCT01188785 \\
\hline & & & $2012^{\dagger}$ & ॥ & Pancreatic cancer & & NCT01676259 \\
\hline
\end{tabular}

\section{How do siRNA carriers cause nanotoxicity?}

siRNA nanocarriers for systemic delivery are developed to encapsulate siRNAs, stay in the circulation, deliver the siRNA payload to the target cells, interact with the cell surface, enter the cell and efficiently escape the endosome-lysosome system to unload the siRNAs to the cytoplasm $[12,13]$. To efficiently perform this series of tasks, researchers have introduced features to the nanocarriers that include surface modification with PEG (i.e., 'PEGlyated') to extend their circulation time [28], controlled siRNA release optimization [29,30], inclusion of cationic materials or targeting moieties to improve carrier-cell interactions [31,32], addition of ingredients to enhance endosomal escape [33] or a combination of all of these $[13,34]$. From a toxicological perspective, the 
REVIEW Xue, Liu \& Wong
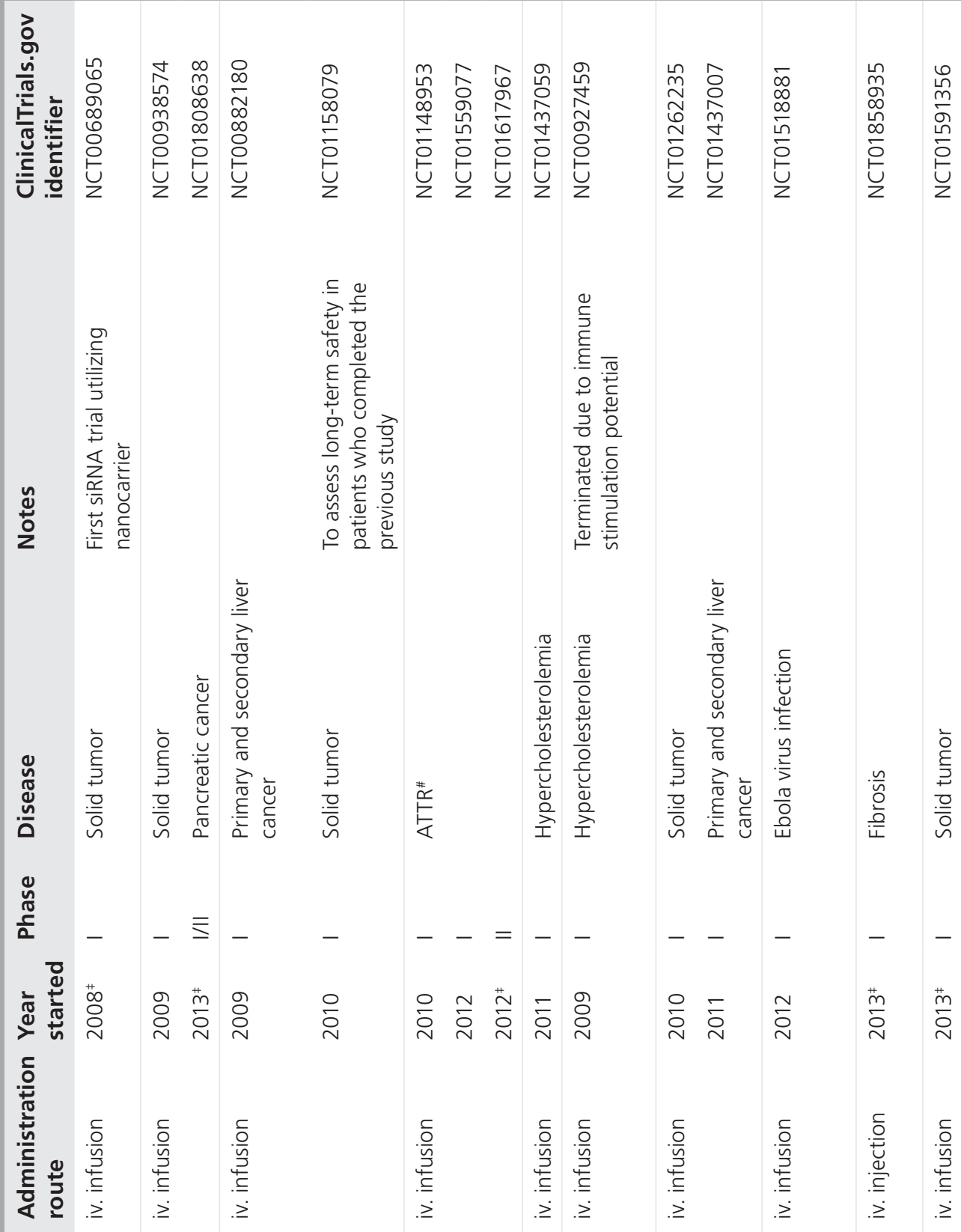

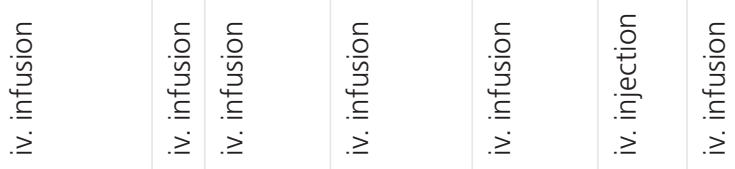

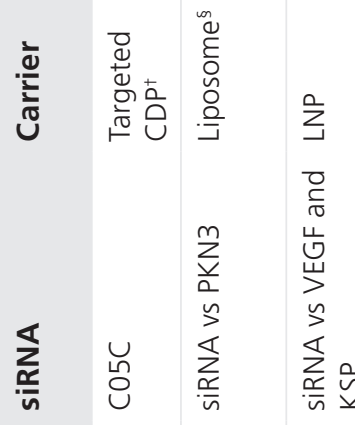

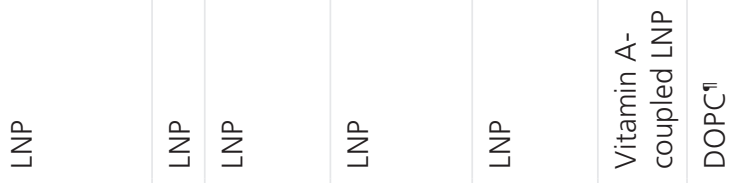

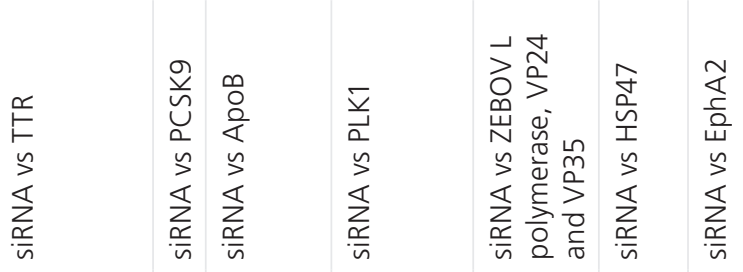

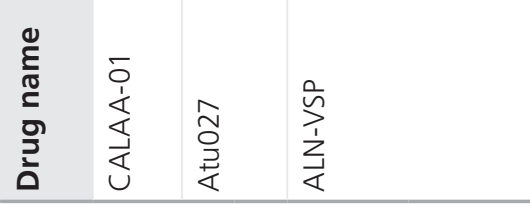

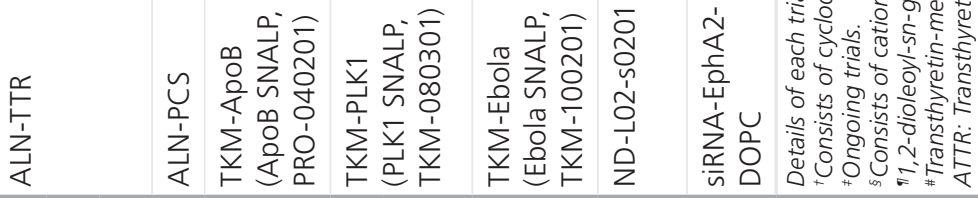


high complexity of nanocarriers can be counterproductive. Each additional feature implies an extra risk of toxicity.

TABLE 4 summarizes the ways in which high levels of these complex nanodevices can lead to toxicity. Most siRNA carriers contain cationic ingredient(s) because cationic functional groups enable electrostatic complexation and better encapsulation of the polyanionic siRNA molecules. The positive charges can facilitate interaction with the negatively charged cell surface $[35,36]$. Cellular damage can be caused by direct interactions between the cationic groups and cellular components, or indirectly by reactive oxidative species (ROS) formed in the presence of cationic materials. The resulting cell toxicity can be manifested in an acute or delayed manner [37]. It should be noted that the mechanism about how cationic nanomaterials cause cytotoxicity is still not well understood and an alternative mechanism has been proposed [38]. Other obvious damage includes 'lysosomal overload' of poorly biodegradable nanocarriers, which results in the accumulation of visible autophagic vacuoles and apoptotic cell death [39].

In addition to cationic materials, production of ROS, such as hydrogen peroxide, superoxide anions and hydroxyl radicals, can also be triggered by noncationic nanomaterials (e.g., carbon nanotubes [CNTs] and metallic nanocarriers) or impurities (e.g., heavy metals) in the nanocarriers $[40,41]$. Since the high surface area of nanomaterials tends to promote ROS formation, it has been suggested that oxidative stress is a particularly significant mechanism responsible for nanotoxicity at the cellular level [40]. High levels of intracellular ROS can react with a diversity of cellular macromolecules including DNA, proteins and membrane lipids. Based on the studies of CNTs, this could activate a number of molecular signaling pathways, including AP-1, and NF- $\kappa$ B and MAPK, which leads to the release of proinflammatory cytokines together with the depletion of antioxidant defenses, such as PARP1, p38 and serine-threonine kinase (Akt). The risk of cell death is therefore increased [42].

Many siRNA nanocarriers, not just CNTs, can stimulate the immune system via Toll-like receptor activation [43]. Secretion of cytokines and chemokines (e.g., TNF- $\alpha$, IL-1 $\beta$, IL-6, IL-10 and MCP1) can promote local inflammation. At in vivo and clinical levels this may recruit neutrophils that secrete additional proinflammatory cytokines (e.g., TNF- $\alpha$ and IL-1 $\beta$ ). Other related cells such as macrophages and lymphocytes may also be attracted to the sight of inflammation. While the immunostimulatory phenomenon can be exploited for therapy, more often it may lead to undesirable outcomes such as incompatibility of the blood and the nanocarriers, hypersensitivity reactions andinflammatory responses and anaphylaxis due to suppressed immune defense [43]. Excessive inflammatory

\section{Table 3. Key factors that modify nanocarrier toxicity.}

\begin{tabular}{|c|c|c|}
\hline Factor & Example & Ref. \\
\hline Shape & $\begin{array}{l}\text { Long, needle-shaped carbon nanotubes are more cytotoxic than } \\
\text { shorter ones }\end{array}$ & {$[97]$} \\
\hline Size & $\begin{array}{l}\text { Intermediate size (e.g., } 8-37 \mathrm{~nm}) \text { gold NPs caused higher in vivo } \\
\text { toxicity in mice than very small (e.g., } 3 \mathrm{~nm} \text { ) and large } \\
\text { (e.g., } 100 \mathrm{~nm} \text { ) ones }\end{array}$ & {$[89]$} \\
\hline Surface charge & $\begin{array}{l}\text { Neutral gold NPs caused cell death through necrosis, whereas } \\
\text { charged nanoparticles induced apoptotic cell death }\end{array}$ & {$[25]$} \\
\hline $\begin{array}{l}\text { Surface } \\
\text { hydrophobicity/hydrophilicity }\end{array}$ & $\begin{array}{l}\text { Hydrophobic modifications of NPs caused a severe inflammatory } \\
\text { response }\end{array}$ & {$[106]$} \\
\hline Nanocarrier ingredients & $\begin{array}{l}\text { Nanocarriers made of linear, low-molecular-weight PEls caused } \\
\text { less inflammatory responses than those made of branched, } \\
\text { high-molecular-weight PEls }\end{array}$ & {$[26]$} \\
\hline Route of exposure & $\begin{array}{l}\text { Direct systemic administration is associated with the highest risk } \\
\text { of systemic toxicity due to accumulation of nanomaterials in the } \\
\text { vital organs, such as the liver and kidneys. Other routes } \\
\text { (e.g., topical, inhaled or oral) generally cause local toxicity at the } \\
\text { sites of exposure, but can also lead to significant systemic toxicity } \\
\text { if the nanomaterials are small enough }(<100 \mathrm{~nm}) \text { to penetrate the } \\
\text { barrier structures (e.g., skin and Gl tract) }\end{array}$ & {$[27]$} \\
\hline
\end{tabular}




\section{Table 4. Common types of toxicity mediated by siRNA nanocarriers.}

\section{Cause}

Significant direct damage to cell membrane integrity

Significant direct damage to critical cellular components, for example, chromosomes and mitochondria

Oxidative stress induced

Nanocarriers overloading the lysosomes, for example, owing to poor biodegradability or inhibitive effects on lysosomal enzymes

Altered gene expression (i.e., toxicogenomics)

Genotoxicity

Immunogenic response stimulated

\section{Outcome}

Trigger acute cell death by necrosis and cell lysis within a short time (e.g., hours) after nanocarrier exposure, may initiate inflammatory responses to surrounding tissues

Trigger apoptotic cell death, typically a few days after nanocarrier exposure Induce production of ROS. Moderate level of ROS causes DNA damages and lipid peroxidation; high level of ROS may trigger apoptosis. ROS generation is related to the nanomaterial, nanoparticle surface area and impurities in the nanodevices

Leads to accumulation of visible autophagic vacuoles and autophagic dysfunction. Significant autophagy increases risk of apoptotic cell death

From subtle disturbance of normal cell functions and phenotypes to measurable reduction in cell proliferation and even cell death

Certain nanocarriers (e.g., carbon nanotubes) can localize with the cell nucleus and induce DNA strand breakage

Reduce compatibility of the nanocarriers with the blood, mild-to-severe (anaphylaxis) hypersensitivity reactions, inflammatory responses (e.g., cytokine production), anaphylaxis, suppressed body defense to infection and cancer cell spreading, and myelosuppression (this effect might be exploited for therapy)

Nanocarriers that are poorly designed and made of unfavorable materials may increase the risk of Toll-like receptor activation by siRNAs during the endosomal escape process, triggering cytokine production responses can inflict significant damages to tissues and organs (e.g., liver toxicity) and can be lethal.

Nanocarrier-mediated toxicity can also occur in more obscure manners. At the cell level, nanocarriers can alter gene expression, a phenomenon known as toxicogenomics, and subtly disturb normal cell functions and phenotypes in a detrimental manner [44]. It should be noted that severe disturbance of the expression of key proteins (e.g., p53, Rad51 and OGG1) can eventually cause cell mortality and noticeable tissue damage. Localization of very small nanocarriers in the cell nucleus can also induce DNA strand breaks (i.e., genotoxicity), and trigger cell death if it is excessive [40].

\section{Nanotoxicity of the major classes of siRNA carriers}

Cationic charges in siRNA carriers can be provided by various materials, most typically polymers, lipids and inorganic nanomaterials.

\section{Polymer- \& dendrimer-based nanocarriers}

Polymers such as polyethylenimine (PEI), polyL-lysine, poly-L-arginine, chitosan and their derivatives have been commonly used for siRNA nanocarrier development [45]. In addition, a class of highly branched, symmetric polymerlike macromolecules of 5-20 $\mathrm{nm}$ in size, known as dendrimers, have recently gained popularity for nucleic acid delivery [45]. Examples of dendrimers used for siRNA delivery include polypropylenimine (PPI) and polyamidoamines. These polymers and dendrimers have multiple cationic groups to facilitate complexation with siRNAs and enhance their endosomal escape using the proton-sponge effect $[45,46]$.

Among the cationic polymers, PEI has been the standard for nucleic acid delivery owing to its good cell membrane interaction, high cellular uptake rate and efficient endosomal escape [47]. PEI is available in several molecular weight grades and in branched or linear structures, with $25-\mathrm{kDa}$ branched PEI being traditionally used most for siRNA delivery [45]. However, PEIs generally exhibit significant in vitro and in vivo toxicity. Free, uncomplexed PEI molecules can interact with negatively charged serum proteins and even red blood cell surfaces, to form aggregates to adhere to tissue surfaces to inflict acute cell damage. PEI molecules can also be released from polyplexes internalized by cells and interact with cellular components to cause delayed toxicity [48]. 
High-molecular-weight PEIs are more toxic. PEIs below $10 \mathrm{kDa}$ generally have lower toxicity [49]. Branched PEIs often cause more cellular toxicity than the linear ones with similar molecular weights [45,50]. It was suggested that this is partly due to the higher efficacy of the branched PEIs compared with their linear counterparts. For instance, a study comparing branched PEIs with linear PEIs of the same molecular weight showed that branched PEIs induced stronger apoptotic responses in A431 cells both at early and late stage, resulting in more DNA damage and Akt kinase induction [51]. The only major difference between the two PEIs was that the branched form was more internalized by the cells. Similar findings were reported in nondifferentiated fibroblast COS-1 cells [52].

However, other studies on PEI/DNA polyplexes showed that linear PEIs actually have both superior transfection efficiency and toxicity profiles [50,53]. The contradictory findings are probably attributable to the differences in the experimental conditions (e.g., in vitro vs in vivo) and the manner in which the polyplexes were prepared. The polyplexes formed by linear PEIs under salt-free conditions were found to be highly efficacious in vivo. Another report showed that while the proinflammatory activities of PEIs were independent of their structure, linear PEIs could be prepared at a higher N:P ratio (up to 25) to achieve improved in vivo efficacy, whereas branched PEI became lethal to the animals when the N:P ratio was higher than 15 . Therefor, that linear PEIs will be more suitable for clinical use.

PEI toxicity is partly due to its limited biodegradability $[37,45]$. Hydrolysable analogous polymers with degradation half-lives in days, such as poly(amino esters), have, therefore, been developed [54]. It was shown that poly(amino ester) carrier achieved nearly a 1.5-times better genesilencing effect and significantly lower cytotoxicity than $25-\mathrm{kDa}$ PEIs. Other hydrolysable polymers such as poly(ester amine) and poly(amido amine) were also studied. Tzeng et al. tested them on human umbilical vein endothelial cells and demonstrated a $60-75 \%$ siRNA-mediated knockdown of GFP with high cell viability [55].

Currently, the most successful synthetic cationic polymer used for siRNA delivery is probably a linear cyclodextrin-based polymer containing polycation (CDP) [56,57]. In a nonhuman primate study, cynomolgus monkeys were systemically administered with CDP containing 3 , 9 or $27 \mathrm{mg}$ siRNA/kg [57]. Only mild elevations levels of the indicators of kidney toxicity (blood urea nitrogen and creatinine) and liver toxicity (ALT or AST) were observed at the highest dose level. Increases in IL-6 level in all animals and IFN- $\alpha$ in one animal was also detected, which is indicative of a modest immune response to the treatment. Meanwhile, there were no clinical signs of toxicity, changes in complement factors and hypersensitivity detected. The data indicated that except for a slight risk of dosedependent toxicity in vivo, systemic use of CDPsiRNAs is safe. These favorable findings have propelled CDP-siRNA drugs onto the clinical stage [58]. In a Phase I trial in patients with solid refractory cancers, only grade 1-2 fatigue, fever/chills and gastrointestinal symptoms were observed at all dose levels, and transient increases in IL- 6 and TNF- $\alpha$ were reported at the highest dose level [59]. Overall, this siRNA nanoformulation appeared to be well tolerated.

The concern for toxicity of synthetic polymers has led some researchers to explore other options, such as natural polymers and dendrimers. Chitosan, a naturally occurring polysaccharide composed of glucosamine and $N$-acetylglucosamine residues derived from the partial deacetylation of chitin, has been particularly studied owing to its low cell toxicity and immunogenicity and the polymer and chitosan/siRNA complexes [60,61]. Initially, there were concerns for the colloidal stability and encapsulation efficiency of chitosan owing to inadequate ionic complexation between this polysaccharide and nucleic acid molecules [62]. Chitosan is also less efficient than other cationic polymers, such as PEI, in terms of endosomal escape owing to its relatively weak buffering capacity [63]. However, these issues have been addressed by the optimization of the nanocarrier process, proper choice of chitosan (e.g., high molecular weight chitosans are more efficient than low molecular weight chitosans in delivering siRNA [64]) and modification of the native chitosan, such as introducing secondary and tertiary amines to increase the endosomal buffering capacity [65].

Chitosan-based nanocarriers have been shown to be a promising choice for siRNA delivery not only in vitro but also in vivo [66]. For instance, Salva et al. showed that siRNA chitosan nanocomplexes targeting VEGF demonstrated significant knockdown effects on VEGF expression and tumor size in a rat breast cancer model [66]. From the toxicological perspective, chitosan nanosystems were shown to have minimal cytotoxicity and did not induce proinflammatory cytokines in vitro. Recent studies also showed that chitosan-based materials have low in vivo 
allergenic potential [67]. It was found that they could downregulate type 2 allergic responses increasing type 1 cytokines (e.g., IL-12 and IL-18) production. In conclusion, based on the physicochemical properties, transfection efficacy and the toxicity data, chitosan has strong clinical potential for siRNA delivery.

Cationic dendrimers such as PPI have emerged as siRNA carriers due to their easily modifiable physicochemical properties [45]. The cytotoxicity of PPI is thought to be low [68], but it was later showed that PPI can modify the expression of several genes in a manner that is related to the dendrimer generation [69]. In A431 cells exposed to the generation 3 PPI $(D A B$ 16 ), the expression of genes including $A N X A 2$, CDK4, CD27 antigen, RPA3, DUSP1, HSPD1, proteasome 4, and cellular enzymes including ALOX5, GMPS and TH were all found altered using microarrays. In comparison, the generation 2 PPI (DAB-8) only altered the expression of one gene, probably as a result of lower surface charge [70]. The toxicogenomic activity of other dendrimers such as polyamidoamines was also found to be adjustable by varying the conditions of their synthesis [71], suggesting that the toxicity of dendrimer-based nanocarriers can be reduced to an acceptable level by proper optimization.

\section{Lipid-based nanocarriers}

The cell membrane is rich in lipids and phospholipids, therefore, it is a logical choice to use lipids as materials to build nucleic acid delivery systems that demand good interaction with the cell surface. Cationic lipids have been widely used for DNA transfection for decades [37,72], with $N$-[1-(2,3-dioleoyloxy)]-N-N-N trimethyl ammonium propane (DOTAP) as the most popular choice [73]. After the discovery of RNAi, there has been a general shift of RNAi application from DNA transfection to siRNA delivery. Currently, most of the products commercially available for siRNA transfection, for example, the Lipofectamine ${ }^{\circledR}$ series and Oligofectamine $^{\mathrm{TM}}$ from Invitrogen (CA, USA) and RNAifect from Qiagen (Limberg, The Netherlands) are all cationic lipid based [44].

Unlike polymeric nanocarriers, cationic lipidbased systems often include other noncationic ingredients, for example, neutral lipids. L-alpha dioleoyl phosphatidyl ethanolamine and cholesterol are frequently included to destabilize endosomes for endosomal escape and stabilize the nanocarrier, respectively $[73,74]$. These neutral lipids by themselves are generally less harmful than the cationic components, but may potentiate the overall carrier cytotoxicity in certain formulations [75]. It was reported that 293 A cell viability was reduced from over $80 \%$ to below $60 \%$ when cholesterol was added to a DOTAP nanocarrier. Hence, these apparently harmless ingredients should not be overlooked when considering carrier toxicity.

Most cationic lipid molecules consist of three regions: a cationic head, a hydrophobic hydrocarbon backbone and a linker that connects the head and tail [73]. The whole molecule resembles a detergent, therefore, a high concentration of cationic lipids can compromise the membrane integrity resulting in cell lysis and necrotic death. At a sublethal concentration, the lipoplexes can still cause irritation to the cells and induce cell shrinkage, vacuolization of the cytoplasm and a reduced number of mitoses [76]. The cationic head groups are also capable of interacting with enzymes, such as PKC, to cause cell toxicity [77]. The PKC inhibitory effect was especially high in some cholesterol derivatives that contain tertiary or quaternary nitrogen head groups [78]. It was also shown that lipids with a steroid backbone are more cytotoxic than the straight-chain analogs in vitro [78]. Cationic lipids with stable linkers are more cytotoxic than those with labile linkers (e.g., ester in DOTAP and other hydrolysable linkers in new synthetic lipids) owing to slow degradation in cells [79].

Similar to cationic polymers, cationic lipids also induce undesirable gene expression changes in vitro. It was shown that Oligofectamine formulation upregulated expression of genes involved in the apoptotic process including caspase 8 isoform c, BCL2A1, HSP70 and HSPD1. The effects of Lipofectin ${ }^{\circledR}$ (Invitrogen, CA, USA) on genes were comparatively lower, but it still significantly upregulated RPA1 and triggered suppression of some genes, such as EDNRB1 and 2 and ribosomal protein S16 $[71,80]$. The authors suggested that the altered gene expression may lead to an increased tendency towards early apoptosis of the cells.

The preclinical findings on DNA lipoplexes are of some reference value on their in vivo toxicity as siRNA nanocarriers. It was shown that after systemic administration of cationic lipid nanocarriers to animals, mortality occured at high doses [81]. Systemic toxicities mediated by lipoplexes include:

- Inflammatory toxicity: lipoplexes are captured by Kupffer cells and trigger the release of proinflammatory cytokines, such as TNF- $\alpha$, IFN- $\gamma$, IL-6 and IL-12; 
- Liver toxicity: damage to liver tissues are indicated by elevated serum levels of transaminases especially ALT and AST;

- Hematologic and serologic toxicity; for example, leukopenia and thrombocytopenia [82].

To prevent similar in vivo toxicity from occurring in siRNA delivery in preclinical studies and clinical trials, several more sophisticated lipid-based nanocarriers were developed. Their success is indicated by the fact that 14 out of 15 trials used lipid-based carriers (Table 2). Currently, LNPs have probably made the biggest progress [20]. LNPs are solid core, electron-dense nanocarriers $\geq 120 \mathrm{~nm}$ made of a combination of cationic lipids, neutral lipids and PEG-conjugated lipids [83]. LNPs have been extensively evaluated in different mammals for in vivo siRNA delivery [83] and clinically evaluated by Tekmira Pharmaceuticals (location) with robust in vivo delivery and siRNA-mediated RNAi activity reported [84,85]. In terms of toxicity, there were no reported treatment-related effects on the animals' appearance or behaviors, as well as no evidence for complement activation, delayed coagulation, proinflammatory cytokine production or changes in hematology parameters [9]. In the apolipoprotein B-LNP trial, it was reported that the formulation was well tolerated with no evidence of hepatotoxicity. However, one out of the two subjects treated at the highest dose level experienced flu-like symptoms consistent with immunostimulation by the siRNA payload. Tekmira thus decided to conclude the trial [85]. It is, therefore, safe to conclude that the risk of toxicity is low but does exist.

\section{Other nanocarriers}

Other materials, mostly inorganic, have been used for siRNA nanocarrier preparation owing to their good stability and physical strength, high purity, reproducible and adjustable size and morphology, ease of surface coating for improved siRNA binding and delivery $[86,87]$.

Gold can form highly stable nanosystems with customizable sizes to facilitate endocytosis by target cells [87]. Gold nanoparticles coated with cationic polymer for siRNA binding generally display low cell toxicity. The viability or proliferation rates of several cell lines (A547, SKOV3, Hela and KB) after exposure to polymer-stabilized siRNA-loaded gold nanoparticles were similar to the free siRNA control [88]. However, caution must be exercised as nanotoxicity was previously reported in non-siRNA gold nanosystems in vitro and in vivo. Gold-mediated nanotoxicity may be size dependent and affected by the presence of serum proteins [89]. It is probably safer to assume that every gold-based nanocarrier requires careful assessment of its toxicity on an individual basis.

Iron oxide nanoparticles are promising for siRNA delivery as they can also be functionalized with cationic materials [90], and their magnetic properties allow tracking by MRI techniques [90,91]. In terms of toxicity, iron oxide is considered biocompatible and biodegradable, and dextran-coated iron oxide nanoparticles have already been approved by the US FDA for clinical purposes [92]. Surface-functionalization and siRNA complexation appear to not make these nanoparticles more toxic in vitro [91]. Lipoid-coated iron oxide nanocarriers of siRNAs were tested in ten gastric cancer cell lines, common COS-7 kidney fibroblasts and HeLa cervical cancer cell lines, and TKD2 murine endothelial cell lines [93]. The viability of every cell line was over $85 \%$ after treatment. In mice, no evident adverse immune reaction or side effects were observed after administration. In brief, functionalized iron oxide nanoparticles for siRNA are probably safe in vitro and possibly in vivo.

CNTs are helical microtubules of graphitic carbon with outstanding stability and strengthto-weight and aspect ratios [94]. Several CNTbased systems have been developed for siRNA delivery [95] and they generally demonstrated a high delivery efficiency. However, in the past few years their toxicity has been under serious scrutiny [96]. The key issue surrounds their resemblance to asbestos fibers in terms of the high aspect ratio and, hence, pathogenic effects [97]. After intraperitoneal administration, the CNT molecules recruited inflammatory cells and caused thickening of mesothelioma in the lining of abdominal cavity. Needle-like CNTs and asbestos both also activated IL-1 secretion from primed macrophages [98]. It was found that the activation of NLRP3 inflammasomes essential for CNT-induced IL-1 secretion depended on harmful ROS production, CTSB activity, P2X receptor, and Src and Syk tyrosine kinases. Owing to these risks, caution should be exercised when choosing CNTs for siRNA delivery. The CNTs of a longer length should be avoided.

Other inorganic materials used for siRNA delivery include calcium phosphate nanoparticles. Calcium phosphate coprecipitate has been 


\section{Table 5. Summary of strategies for reducing siRNA carrier nanotoxicity.}

\section{Strategy \\ Example \\ Ref.}

Optimization of carrier materials

Use linear, low-molecular-weight Linear PEl induced less proinflammatory cytokines than the branched counterparts polymer

Use polymer with higher biodegradability

siRNA nanocarriers made of biodegradable poly(amino esters) demonstrated significantly higher transfection efficiency and lower toxicity to lung cells when compared with 25-kDa PEI

Use well-established natural polymer

Human lung cancer cells transfected with a chitosan nanosystem demonstrated higher viability than when using a commercial lipid transfection agent

Use bioreducible polymer

Nanocarriers prepared by cross-linking low-molecular-weight linear poly(ethylenimine sulfide) quickly degraded in the reductive intracellular environment and produced degradants that were essentially nontoxic (cell survival 98.69\%)

Engineer cationic lipids based on Lipids containing biodegradable linker had lower inherent cytotoxicity

structure-toxicity analysis

\section{Optimization of physical properties}

Screen for right size

Masking the cationic charges

Increase surface hydrophilicity with PEGlyation

Alternative delivery routes

Low-dose approach based on combinatorial synthesis and screening

Hybrid nanocarrier made of two or more classes of materials

\section{Active targeting}

EGFR targeting

Folate receptor targeting

LHRH peptide-based targeting

Cell-penetrating peptide-based targeting

Gold NPs with the smallest sizes ( 3 and $5 \mathrm{~nm}$ ) and the largest sizes (50 and $100 \mathrm{~nm}$ ) are nontoxic, but the intermediate sizes $(8-37 \mathrm{~nm})$ had lethal effects on mice

PAMAM dendrimer was engineered to keep the cationic charges inside the carrier instead of on the surface, resulting in significantly reduced dendrimer toxicity while improving the in vivo tumor-targeting properties when conjugated with LHRH

After pulmonary administration, it was shown that hydrophilic modifications of PEI nanocarriers with PEG grafting induced fewer proinflammatory effects without depleting macrophages and disrupting the epithelial/endothelial barrier in the lungs

Spherical nucleic acid nanoparticle conjugates applied topically did not cause clinical or histological signs of toxicity or trigger cytokine activation in mouse blood or tissue samples

Highly potent lipidoid-based siRNA nanoparticles allowed low-dose treatment that was well tolerated in mice

Solid lipids in lipid-polymer hybrid nanocarriers reduced the toxicity of PEI components in human breast epithelial cells as indicated by less membrane damage, improved mitochondrial function, reduced reactive oxidative species production and lower caspase-3 activity

\section{Asymmetric liposome particles showed no cell toxicity}

Folate-PEG-grafted siRNA nanocarriers demonstrated favorable cytotoxicity, transfection efficiency and cancer cell specificity compared with PEG-grafted nanocarriers

NPs containing superparamagnetic iron oxide and poly(propyleneimine) dendrimer functionalized with LHRH peptide and PEG demonstrated enhanced serum stability, specific cellular uptake and low toxicity in A549 cells

Chitosan-based siRNA nanocarriers functionalized with PEG and the cell-penetrating peptide TAT exhibited maximum cell transfection ability and very low cytotoxicity in Neuro2a neuroblastoma cells

NP: Nanoparticle; PAMAM: Polyamidoamine; PEl: Polyethylenimine.

traditionally used for in vitro gene transfection owing to its nontoxic nature [99], however, its use for in vivo delivery has been limited by its tendency for rapid particle growth. Recently it was found that bisphophonate derivatives can stabilize calcium phophate nanoparticles for siRNA delivery [99,100]. In these studies no in vitro cell toxicity was observed, however, the in vivo data of this class of nanocarriers was limited.

\section{Strategies to overcome nanotoxicity of siRNA carriers}

Researchers in recent years have been searching for new approaches or techniques to decrease nanotoxicity. These approaches are summarized in Table 5.

\section{Optimization of carrier materials}

Selecting the right materials is critical in lowering carrier toxicity. For polymeric systems, 
owing to the ease of engineering their molecular structures to manipulate their physicochemical and biological properties, a systematic approach can be taken to break the commonly observed efficacy-toxicity correlation. Previous attempts have been made to optimize linear PEIs to increase the transfection efficiency of these relatively less toxic, less immunogenic agents [26,50,53,101]. Recently, Swami et al. have adopted a chemical engineering approach to optimize both the transfection efficiency and toxicity $[102,103]$. They developed PEI-based nanoparticles by introducing ionic and covalent crosslinkers with varying proportions of 1,6-hexanebisphosphate, adipic acid and 1,4-butane dialdehyde to obtain a library of 1,6-hexanebisphosphate-PEIs, adipic acid-PEI and 1,4-butane dialdehyde-PEI nanoparticles, respectively, and characterized this nanoparticle library by spectroscopic technique as well as by physicochemical parameters, such as size, morphology, surface charge, effect of crosslinking on buffering capacity and nucleic acid binding ability. Meanwhile, their cytotoxicity data in various cell lines were obtained, and the efficacy and cytotoxicity of the entire series of nanoparticles was systematically compared with one another to identify the 'best' nucleic acid carrier [102,103].

A 'bioreducible nanocarrier' approach was developed to further resolve the efficacy-toxicity dilemma based on the difference in the redox potential between the extracellular and intracellular environments [104]. It was recognized that disulfide bonds that are stable in systemic circulation can be cleaved in the more reductive intracellular compartment. In Breunig et al.'s study, low-molecular-weight (molecular weight $<4.6 \mathrm{kDa}$ ) linear poly(ethylenimine sulfide) was crosslinked to form high-molecular-weight polymeric siRNA nanocarriers [104]. The resulting nanocarrier was able to provide higher transfection efficiencies in HEK cells and quickly degraded after cellular internalization to produce degradants with less toxicity than seven commercial transfection reagents in seven cell lines. Similar findings were reported in a nanoformulation made of bioreducible poly(amido amine) [105].

For lipid-based systems how to optimize the lipid structures to reduce their toxicity follows fairly complex rules [37]. The key point is that information regarding the structure-toxicity relationship of cationic lipids is mostly derived from their use for in vitro transfection. Hence, it is advisable to use the data in the literature only as a guideline to eliminate the lipid structures that cause excessive toxicity at a cellular level, and not relying on them to choose the 'right' lipids for in vivo or clinical use. Careful in vivo screening remains crucial.

\section{Optimization of physical properties of nanocarriers}

Nanotoxicity can be reduced by optimizing the physical parameters. For example, Chen et al. prepared gold nanoparticles of sizes from 3 to $100 \mathrm{~nm}$ and studied their in vivo toxicity in mice. The smallest and largest particles were nontoxic, but the intermediate sizes $(8-37 \mathrm{~nm})$ had lethal effects on the mice [89]. For lipid- or polymer-based nanocarriers, size optimization can be a challenging strategy because their sizes are often a function of their chemical composition. It is difficult to achieve the desirable size while keeping all other properties constant.

Surface charge and hydrophobicity/hydrophilicity can be manipulated to ameliorate carrier toxicity. Cationic charges on nanocarriers were masked to reduce their damaging effects, for example, using lipids with heterocyclic rings to facilitate charge delocalization, or engineering the nanocarrier to keep the cationic charges inside [90]. To modify the surface hydrophobicity, a common practice is to increase the hydrophilicity by PEGlyation. Beyerle et al. developed six different PEI-based nanocarriers with hydrophobic and hydrophilic PEG modifications and evaluated them in the lungs of mice by intratracheal instillation [106]. They showed that hydrophobic modifications caused a severe inflammatory response, while hydrophilic PEG grafting induced less proinflammatory effects without depleting macrophages and disrupting the pulmonary epithelial/endothelial barriers. The findings indicate that PEGlyation not only extends circulation time, but also reduces local tissue toxicity.

\section{- Alternative delivery routes}

In principle, siRNA therapy of many local diseases does not require systemic administration. Local siRNA therapy is difficult because naked siRNAs cannot permeate across the barrier structures such as stratum corneum of the skin. The drug trafficking effects of nanocarriers can help siRNAs to overcome these barriers. Zheng et al. prepared nanoparticles with gold cores functionalized with immobilized anti-EGFR-siRNAs [107]. They demonstrated good penetration through $100 \%$ of keratinocytes in vitro, mouse skin and human epidermis within hours after application, without clinical or histological signs 
of toxicity, cytokine activation and accumulation in the internal organs.

\section{Low-dose approach based on} combinatorial synthesis \& screening

Substantial reduction in siRNA dose can be achieved through the combinatorial synthesis and screening of nanomaterials. Love et al. screened and identified a formulation that could achieve liver gene silencing at doses as low as less than $0.01 \mathrm{mg}$ siRNA $/ \mathrm{kg}$ in mice and at $0.03 \mathrm{mg}$ siRNA/kg in nonhuman primates [108]. It was suggested that in humans, the siRNA dose could be reduced from over $100 \mathrm{mg}$ to lower than $1 \mathrm{mg}$, along with a concomitant reduction in the nanocarrier excipients. As a result, the tolerability to the siRNA nanoformulations can be substantially improved.

\section{Hybrid nanocarriers}

One recent trend in nanocarrier design is to combine different classes of materials (e.g., lipid and polymer) in its preparation. Several of these 'hybrid' nanocarriers have been developed for siRNA delivery [29,30]. Solid lipids are known for their controlled release effects and good biocompatibility even compared with poly(lacticco-glycolic) acid [109]. These properties were exploited in lipid-polymer hybrid nanocarriers (LPNs). In LPNs, alkylated PEI polymers complexed with siRNAs were incorporated into solid lipids. The polymer improved siRNA encapsulation while the lipids facilitated controlled intracellular siRNA release. In toxicity studies comparing LPNs to the unencapsulated PEIs, it was shown that the lipids reduced both the acute and delayed cytotoxicities of the polymeric components $[29,110]$. It was suggested that lipid encapsulation of cationic polymers allows control over the release kinetics of the toxic polymers so damage inflicted to the cell membrane and intracellular organelles is reduced.

There are other similar low toxicity lipid-polymer hybrid systems such as the polycation liposomes [111]. Hybrid nanocarriers that merge other combinations of materials were also developed. For example, it was found that by tightly coating PEI onto the gold nanoparticle surface and/ or covered by a protein corona [112], the in vitro PEI toxicity was significantly reduced, suggesting that binding of a material to the nanoparticle surface could modulate its toxicity.

\section{Active targeting}

Many toxicity problems of siRNA carriers derive from their lack of cell/tissue specificity. For certain diseases, such as cancer, passive targeting based on an enhanced permeation and retention effect can increase tumor drug accumulation [113], however, the improvement is often moderate. Therefore, siRNA nanocarriers developed in recent years have often been functionalized with active-targeting moieties, such as monoclonal antibodies, receptor substrates and cellpenetrating peptides $[90,114-116]$. The advantage of this active-targeting strategy is illustrated in the study of asymmetric liposome particles, which were designed with the positive charges on the inner surface to minimize the nonspecific cellular uptake [114]. Only after decorating asymmetric liposome particles with anti-EGFR could receptor-mediated uptake into lung cancer cell lines but not into the EGFR-free NIH-3T3 cells be effectively induced. More examples of active targeting are listed in TabLe 5 .

\section{Current methodology for nanotoxicity evaluation}

To develop a siRNA carrier with acceptable nanotoxicity, one of the biggest challenges is finding the proper way to evaluate the toxic effect, so the toxicity assessment is accurate and the information extracted clinically relevant. Currently, this challenge has not been adequately met. Several problematic practices are frequently observed:

- In vivo evaluation is briefly covered. In vitro characterizations do not account for the complexity of in vivo systems [117];

- For in vitro studies, toxicity evaluation is often only performed on the target cells, for example, anticancer siRNA nanoformulations are only tested on the cancer cells that are supposed to get killed, while other vulnerable cell types are neglected;

- In vitro toxicity evaluation is focused on shortterm cell viability. Other outcomes such as long-term cell proliferation, cell organelle damage, genomic changes and immunogenic responses are seldom measured;

- The experimental conditions (e.g., dose levels, dose frequency, treatment duration and cell models) may not be therapeutically relevant;

- The toxicity of a nanoformulation can be affected by its exact composition, but toxicological evaluation is often performed on a nanocarrier with a siRNA payload, siRNA sequence (e.g., siRNA for mouse instead of human) or degree of functionalization different from the one to be clinically tested. 


\section{Table 6. In vitro immunology assays used in the Nanotechnology Characterization Laboratory.}

\section{Test}

Blood contact properties

Analysis of hemolytic properties of NPS

Analysis of platelet aggregation

Analysis of NP interaction with plasma proteins by 2D PAGE

Qualitative analysis of total complement activation by western blot

Quantitative analysis of complement activation

Coagulation assay

\section{Cell-based assays}

Mouse granulocyte macrophage

colony-forming unit assay

Leukocyte proliferation assay

Detection of nitric oxide production by

RAW 264.7 macrophage cell line

Measurement of NP effects on cytotoxic activity of NK cells

Analysis of NP effects on maturation of monocyte derived DCs

In vitro induction of leukocyte procoagulant

\section{Oxidative stress}

Hep G2 hepatocyte glutathione assay

Hep G2 hepatocyte lipid peroxidation assay

Hepatocyte primary ROS assay activity by NPS

\section{Goal}

Primary hepatocytes

Normal human whole blood

Sodium citrate human whole blood

Sodium citrate human whole blood

Sodium citrate human plasma

Sodium citrate human plasma

Sodium citrate human whole blood

Hematopoietic stem cells

Human lymphocytes

RAW 264.7 murine macrophages

NK92 cells/hepatocarcinoma HepG2 cells

Human peripheral blood mononuclear cells

HL-60 cells

Hep G2 cells

Hep G2 cells
Colorimetric determination of hemoglobin released from red blood cells after NP exposure

Screening of potential anticoagulant or thrombogenic properties of NPs

Evaluate protein adsorption on NPs that increases risk of opsonization by macrophages

Qualitative determination of total complement activation by western blot analysis

Quantitative determination of complement activation by an enzyme immunoassay

Assess the NP effects on plasma coagulation time

Assess the effects of NPs related to myelosuppression

Measure NP effects on lymphocyte proliferation

Measure effect of NPs on production of cytotoxic nitric oxide by macrophages

Study NP's effect on the cytotoxicity of NK cells

Measure NP effects on DC maturation in response to inflammatory stimuli, such as endotoxin

Assess the ability of NPs to induce leukocyte procoagulant activity

Analyze NP effects on reduced and oxidized glutathione

Analyze NP effects on formation of lipid peroxidation products such as malondialdehyde

Measure NP effects ROS generation by fluorescence spectrophotometry

Measure NP cytotoxic effects on liver cells by MTT and $\mathrm{LDH}$ release assay

Measure NP apoptotic effects (caspase 3 activation) on liver cells

Hep G2 cells

Measure NP apoptotic effects (caspase 3/7 activation) on liver cells

Porcine proximal tubule cells (LLC-PK1)

Measure NP cytotoxic effects on kidney cells by MTT and $\mathrm{LDH}$ release assay

LLC-PK1 cells

Measure NP apoptotic effects (caspase 3 activation) on kidney cells activation)

\section{Autophagy}

Autophagic dysfunction in LLC-PK1 cells LLC-PK1 cells

Evaluate NP effects on causing lysosomal dysfunction using lysotracker dye

Qualitative analysis of MAP LC3I to LC3-II LLC-PK1 cells conversion by western blot

Evaluate NP effects on causing lysosomal dysfunction by immunoblotting 
Currently, there is no well-agreed standard for nanotoxicity evaluation, but some progress has been made [118]. For in vitro evaluation, the assay cascade used by the Nanotechnology Characterization Laboratory, a laboratory established by the National Institute of Cancer, provides a good starting point [205]. TABLE 6 lists the assays the Nanotechnology Characterization Laboratory recommends for in vitro evaluation of a nanosystem's immunogenicity and toxicity. Please note that these assays place strong emphasis on the blood, liver and kidney cells, the most vulnerable targets of systemically administered nanocarriers.

The methodology for in vivo toxicological evaluation is even more varied [117]. In addition to the standard indicators of health, such as bodyweight and physical activity, assays of liver function enzymes and proinflammatory cytokines are probably appropriate choices considering that many siRNA nanocarriers tend to accumulate in liver and cause damage and induce inflammatory responses $[82,101]$. Measurement of the levels of creatinine and blood urea nitrogen should also be included to assess kidney damage. For carriers administered by alternative routes, such as topical or pulmonary, evaluation of local tissue toxicity by histological methods will be essential.

\section{Conclusion}

More than a decade after the discovery of siRNAs, clinical translation of these highly promising biomolecules has approached the make-or-break point. Key challenges arise from the siRNA molecules themselves and the tools for siRNA delivery. Work has already been conducted to overcome the inherent shortcomings of the siRNA molecules such as their offtarget effects and poor stability. The next step will be to solve their delivery issues and this calls for development of reliable siRNA nanocarrier systems. In the past researchers tended to focus on their transfection efficiency and biodistribution, with relatively less attention paid to the 'negative' aspects, such as nanotoxicity and immunogenicity. As an increasing number of siRNA products are approaching clinical trials this issue can no longer be overlooked, due to the growing concern for safety and quality control. By addressing carrier nanotoxicity issues, it will help clear the way for siRNA-based drugs to eventually fulfill their promise as a versatile class of therapeutic agents for diverse gene-related diseases even on personalized basis.

\section{Future perspective}

In near future, it is foreseeable that there will be a better understanding of the mechanisms on how siRNA nanocarriers cause toxicity so novel strategies can be developed to specifically address these problems. This will help reduce or nullify carrier nanotoxicity without sacrificing their therapeutic and delivery efficiency. The true effectiveness of these toxicity reduction strategies, however, cannot be accurately assessed without the proper methodology for toxicological evaluation. It is anticipated that better standards, techniques and tools for nanotoxicity evaluation will be developed, leading to accurate screening of siRNA carriers in a faster, cheaper and more clinically relevant manner. This will also help to establish the standards for good manufacturing practice during and after their clinical development.

\section{Executive summary}

- The therapeutic potential of siRNAs for a broad range of diseases has already been well demonstrated by bench studies in the past decade. Clinical translation has become the current priority for siRNA research.

- Inefficient delivery of siRNAs is often identified as a key obstacle against their clinical translation. Several classes of nanocarriers made from polymers, lipids, inorganic materials or a combination of these have been developed to improve siRNA delivery.

- Many 'inert' materials become harmful to the human body at organ, tissue and cell levels once they are downsized to a nanoscale, which results in nanotoxicity.

- Nanotoxicity can be caused by the disruption of cell membrane integrity, damage to critical cell organelles, production of reactive oxidative species, lysosomal overload, altered gene expression and stimulation of immunogenic responses.

- Nanotoxicity is particularly an issue in siRNA nanocarrier development due to their polycationic charges, complex design and strong interaction with cells and tissues; however, this issue is often overlooked.

- Many polymeric and lipid-based siRNA nanocarriers have multiple cationic groups that are associated with significant toxic effects. A chemical engineering approach has been studied to systematically develop less toxic nanomaterials. The use of low molecular weight, hydrolysable, bioreducible, well-established natural materials or inorganic matters are also appealing options.

- Several other nanotoxicity reduction strategies include optimization of physical properties of nanocarriers, use of an alternative route of administration, a low-dose approach and the development of safer hybrid nanocarriers.

- Currently, there is no well-agreed standard for nanotoxicity evaluation. Researchers have begun to realize that toxicity is an issue and more accurate and clinically relevant methodology is being developed for nanotoxicity assessment. 


\section{Financial \& competing interests disclosure}

This work was supported by a NIH/National Cancer Institute R01 grant (grant no. R01CA168917). The authors have no other relevant affliations or financial involvement with any organization or entity with a financial interest in or financial conflict with the subject matter or materials discussed in the manuscript apart from those disclosed.

No writing assistance was utilized in the production of this manuscript.

\section{References}

Papers of special note have been highlighted as: - of interest

1 Mello CC, Conte D Jr. Revealing the world of RNA interference. Nature 431(7006), 338-342 (2004).

2 Fire A, Xu S, Montgomery MK, Kostas SA, Driver SE, Mello CC. Potent and specific genetic interference by double-stranded RNA in Caenorhabditis elegans. Nature 391(6669), 806-811 (1998).

3 Castel SE, Martienssen RA. RNA interference in the nucleus: roles for small RNAs in transcription, epigenetics and beyond. Nat. Rev. Gene 14(2), 100-112 (2013).

4 Blake SJ, Bokhari FF, McMillan NA. RNA interference for viral infections. Curr. Drug Targets 13(11), 1411-1420 (2012).

5 Kumar LD, Clarke AR. Gene manipulation through the use of small interfering RNA (siRNA): from in vitro to in vivo applications. Adv. Drug Deliv. Rev. 59, 87-100 (2007).

6 Musacchio T, Torchilin VP. siRNA delivery: from basics to therapeutic applications. Front. Biosci. 18, 58-79 (2013).

7 Seth S, Johns R, Templin MV. Delivery and biodistribution of siRNA for cancer therapy: challenges and future prospects. Ther. Deliv. 3(2), 245-261 (2012).

8 Kaur IP, Sharma G. siRNA: a new approach to target neuropathic pain. Biodrugs 26(6), 401-412 (2012)

9 Huda R, Tüzün E, Christadoss P. Complement C2 siRNA mediated therapy of myasthenia gravis in mice. J. Autoimmun. 42, 94-104 (2013).

10 Novobrantseva TI, Borodovsky A, Wong J et al. Systemic RNAi-mediated gene silencing in nonhuman primate and rodent myeloid cells. Mol. Ther. Nucleic Acids 1, e4 (2012).

11 Daka A, Peer D. RNAi-based nanomedicines for targeted personalized therapy. Adv. Drug Deliv. Rev. 64(13), 1508-1521 (2012).

12 Zhao J, Mi Y, Feng SS. siRNA-based nanomedicine. Nanomedicine (Lond.) 8(6), 859-862 (2013).

13 Kesharwani P, Gajbhiye V, Jain NK. A review of nanocarriers for the delivery of small interfering RNA. Biomaterials 33(29), 7138-7150 (2012).
14 Ni Z, Hui P. Emerging pharmacologic therapies for wet age-related macular degeneration. Ophthalmologica 223(6), 401-410 (2009).

15 Semizarov D, Frost L, Sarthy A, Kroeger P, Halbert DN, Fesik SW. Specificity of short interfering RNA determined through gene expression signatures. Proc. Natl Acad. Sci. USA 100, 6347-6352 (2003).

16 Gantier MP. Strategies for designing and validating immunostimulatory siRNAs. Methods Mol. Biol. 942, 179-191 (2013).

17 Morrissey DV, Blanchard K, Shaw L et al. Activity of stabilized short interfering RNA in a mouse model of hepatitis $B$ virus replication. Hepatology 41, 1349-1356 (2005).

18 Iversen F, Yang C, Dagnæs-Hansen F, Schaffert DH, Kjems J, Gao S. Optimized siRNA-PEG conjugates for extended blood circulation and reduced urine excretion in mice. Theranostics 3(3), 201-209 (2013).

19 Tan M, Vernes JM, Chan J et al. Real-time quantification of antibody-short interfering RNA conjugate in serum by antigen capture reverse transcription-polymerase chain reaction. Anal. Biochem. 430(2), 171-178 (2012).

20 Rossi JJ. RNAi therapeutics: SNALPing siRNAs in vivo. Gene Ther. 13 (7), 583-584 (2006).

21 Santamaria A. Historical overview of nanotechnology and nanotoxicology. Methods Mol. Biol. 926, 1-12 (2012).

- Provides a detailed overview on the historical aspect of nanotoxicology.

22 Raemdonck K, Vandenbroucke RE, Demeester J, Sanders NN, de Smedt SC. Maintaining the silence: reflections on long-term RNAi. Drug Discov. Today 13, 917-931 (2008).

23 Voytek P, Anver M, Thorslund T, Conley J, Anderson E. Mechanisms of asbestos carcinogenicity. Int. J. Toxicol. 9 (5), 541-550 (1990).

24 Monteiller C, Tran L, MacNee W et al. The pro-inflammatory effects of low-toxicity lowsolubility particles, nanoparticles and fine particles, on epithelial cells in vitro: the role of surface area. Occup. Environ. Med. 64(9), 609-615 (2007).

25 Schaeublin NM, Braydich-Stolle LK, Schrand AM et al. Surface charge of gold nanoparticles mediates mechanism of toxicity. Nanoscale 3(2), 410-420 (2011).

26 Kawakami S, Ito Y, Charoensit P, Yamashita F, Hashida M. Evaluation of proinflammatory cytokine production induced by linear and branched polyethylenimine/plasmid DNA complexes in mice. J. Pharmacol. Exp. Ther. 317, 1382-1390 (2006).

27 Ai J, Biazar E, Jafarpour M et al. Nanotoxicology and nanoparticle safety in biomedical designs. Int. J. Nanomedicine 6, 1117-1127 (2011)

28 Malhotra M, Lane C, Tomaro-Duchesneau C et al. A novel method for synthesizing PEGylated chitosan nanoparticles: strategy, preparation, and in vitro analysis. Int. J. Nanomedicine 6, 485-494 (2011).

29 Xue HY, Wong HL. Tailoring nanostructured solid-lipid carriers for time-controlled intracellular siRNA kinetics to sustain RNAi-mediated chemosensitization. Biomaterials 32(10), 2662-2672 (2011).

30 Xue HY, Wong HL. Solid lipid-PEI hybrid nanocarrier: an integrated approach to provide extended, targeted, and safer siRNA therapy of prostate cancer in an all-in-one manner. ACS Nano 5(9), 7034-7047 (2011).

31 Yu B, Zhao X, Lee LJ, Lee RJ. Targeted delivery systems for oligonucleotide therapeutics. AAPS J. 11(1), 195-203 (2009).

32 Xue HY, Wong HL. Targeting megalin to enhance delivery of anti-clusterin small-interfering RNA nanomedicine to chemo-treated breast cancer. Eur. J. Pharm. Biopharm. 81(1), 24-32 (2012).

33 Wang M, Li X, Ma Y, Gu H. Endosomal escape kinetics of mesoporous silica-based system for efficient siRNA delivery. Int. J. Pharm. 448(1), 51-57 (2013)

34 Chen $\mathrm{H}$, Zhao $\mathrm{Y}$, Wang $\mathrm{H}$ et al. Co-delivery strategies based on multifunctional nanocarriers for cancer therapy. Curr. Drug Metab. 13(8), 1087-1096 (2012).

35 Ballarin-Gonzalez B. Howard KA. Polycation-based nanoparticle delivery of RNAi therapeutics: adverse effects and solutions. Adv. Drug Deliv. Rev. 64(15), 1717-1729 (2012).

36 Akhtar S. Cationic nanosystems for the delivery of small interfering ribonucleic acid 
therapeutics: a focus on toxicogenomics. Expert. Opin. Drug Metab. Toxicol. 6(11), 1347-1362 (2010).

37 Lv H, Zhang S, Wang B, Cui S, Yan J. Toxicity of cationic lipids and cationic polymers in gene delivery. J. Control. Release 114, 100-109 (2006).

38 Alkilany AM, Nagaria PK, Hexel CR, Shaw TJ, Murphy CJ, Wyatt MD. Cellular uptake and cytotoxicity of gold nanorods: molecular origin of cytotoxicity and surface effects. Small 5, 701-708 (2009).

39 Zabirnyk O, Yezhelyev M, Seleverstov O. Nanoparticles as a novel class of autophagy activators. Autophagy 3, 278-281 (2007).

40 Tsukahara T, Haniu H. Cellular cytotoxic response induced by highly purified multi-wall carbon nanotube in human lung cells. Mol. Cell. Biochem. 352, 57-63 (2011).

41 Pacurari M, Yin X, Zhao J et al. Single-wall carbon nanotubes induceoxidative stress and activate Mapks, AP-1, NF-Kappa b, and Akt in normal and malignant human mesothelial cells. Environ. Health Perspect. 116, 1211-1217 (2008).

42 Liu Y, Zhao Y, Sun B, Chen C. Understanding the toxicity of carbon nanotubes. Acc. Chem. Res. 46(3), 702-713 (2013).

43 Zolnik BS, González-Fernández A, Sadrieh N, Dobrovolskaia MA. Nanoparticles and the immune system. Endocrinology 151(2), 458-465 (2010).

44 Akhtar S, Benter I. Toxicogenomics of non-viral drug delivery systems for RNAi: Potential impact on siRNA-mediated gene silencing activity and specificity. Adv. Drug Deliv. Rev. 59, 164-182 (2007).

45 Singha K, Namgung R, Kim WJ. Polymers in small-interfering RNA delivery. Nucleic Acid Ther. 21(3), 133-147 (2011).

46 Freeman EC, Weiland LM, Meng WS. Modeling the proton sponge hypothesis: examining proton sponge effectiveness for enhancing intracellular gene delivery through multiscale modeling. J. Biomater. Sci. Polym. Ed. 24(4), 398-416 (2013).

47 Nimesh S. Polyethylenimine as a promising vector for targeted siRNA delivery. Curr. Clin. Pharmacol. 7(2), 121-130 (2012).

48 Godbey WT, Wu KK, Mikos AG. Poly(ethyleneimine)-mediated gene delivery affects endothelial cell function and viability, Biomaterials 22, 471-480 (2001).

49 Fischer D, Bieber T, Li Y, Kissel T. A novel non-viral vector for DNA delivery based on low molecular weight, branched polyethylenimine: effect of molecular weight on transfection efficiency and cytotoxicity, Pharm. Res. 16, 1273-1279 (1999).

50 Jäger M, Schubert S, Ochrimenko S, Fischer $\mathrm{D}$, Schubert US. Branched and linear poly(ethylene imine)-based conjugates: synthetic modification, characterization, and application. Chem. Soc. Rev. 41(13), 4755-4767 (2012).

51 Kafil V, Omidi Y. Cytotoxic impacts of linear and branched polyethylenimine nanostructures in A431 cells. Bioimpacts 1(1), 23-30 (2011).

52 Florea BI, Meaney C, Junginger HE, Borchard G. Transfection efficiency and toxicity of polyethylenimine in differentiated Calu- 3 and nondifferentiated COS- 1 cell cultures. AAPS PharmSci. 4(3), E12 (2002).

53 Wightman L, Kircheis R, Rossler V et al. Different behavior of branched and linear polyethylenimine for gene delivery in vitro and in vivo. J. Gene Med. 3, 362-372 (2001).

54 Jere D, Xu CX, Arote R, Yun CH, Cho MH, Cho CS. Poly (beta-amino ester) as a carrier for si/shRNA delivery in lung cancer cells. Biomaterials 29(16), 2535-2547 (2008).

55 Tzeng SY, Yang PH, Grayson WL, Green JJ. Synthetic poly(ester amine) and poly(amido amine) nanoparticles for efficient DNA and siRNA delivery to human endothelial cells. Int. J. Nanomedicine 6, 3309-3322 (2011).

56 Davis ME, Pun SH, Bellocq NC et al. Selfassembling nucleic acid delivery vehicles via linear, water-soluble, cyclodextrin-containing polymers. Curr. Med. Chem. 11, 179-197 (2004).

57 Heidel JD, Yu Z, Liu JY et al. Administration in non-human primates of escalating intravenous doses of targeted nanoparticles containing ribonucleotide reductase subunit M2 siRNA. Proc. Natl Acad. Sci. USA 104, 5715-5721 (2007).

58 Davis ME, Zuckerman JE, Choi CHJ et al. Evidence of RNAi in humans from systemically administered siRNA via targeted nanoparticles. Nature 464(7291), 1067-1070 (2010).

59 Ribas A, Kalinoski L, Heidel JD et al. Systemic delivery of siRNA via targeted nanoparticles in patients with cancer: results from a first-in-class Phase I clinical trial. J. Clin. Oncol. 28(Suppl. 15), Abstract 3022 (2010).

60 Rudzinski WE, Aminabhavi TM. Chitosan as a carrier for targeted delivery of small interfering RNA. Int. J. Pharm. 399(1-2), 1-11 (2010).

61 Anderson MO, Howard KA, Paludan SR, Besenbacher F, Kjems J. Delivery of siRNA from lyophilized polymeric surfaces. Biomaterials 29, 506-512 (2008).
62 Riva R, Ragelle H, des Rieux A, Duhem N, Jerome C, Preat V. Chitosan and chitosan derivatives in drug delivery and tissue engineering, Chitosan Biomater. II 244, 19-44 (2011).

63 Moreira C, Oliveira H, Pires LR, Simões S, Barbosa MA, Pêgo AP. Improving chitosanmediated gene transfer by the introduction of intracellular buffering moieties into the chitosan backbone. Acta Biomater. 5 , 2995-3006 (2009).

64 Liu X, Howard KA, Dong M et al. The influence of polymeric properties on chitosan/siRNA nanoparticle formulation and gene silencing. Biomaterials 28(6), 1280-1288 (2007).

65 Ghosn B, Singh A, Li M et al. Efficient gene silencing in lungs and liver using imidazole-modified chitosan as a nanocarrier for small interfering RNA. Oligonucleotides 20(3), 163-172 (2010).

66 Salva E, Kabasakal L, Eren F, Ozkan N, Cakalagaoglu F, Akbuga J. Local delivery of chitosan/VEGF siRNA nanoplexes reduces angiogenesis and growth of breast cancer in vivo. Nucleic Acid Ther. 22, 40-48 (2012).

67 Muzzarelli RA. Chitins and chitosans as immunoadjuvants and non-allergenic drug carriers. Mar. Drugs 8(2) 292-312 (2010).

68 Duncan R, Izzo L. Dendrimer biocompatibility and toxicity. Adv. Drug Deliv. Rev. 57(15), 2215-2237 (2005).

69 Omidi Y, Hollins AJ, Drayton RM, Akhtar S. Polypropylenimine dendrimer-induced gene expression changes: the effect of complexation with DNA, dendrimer generation and cell type. J. Drug Target. 13(7), 431-443 (2005).

70 Hollins AJ, Benboubetra M, Omidi Y et al. Evaluation of generation 2 and 3 poly(propylenimine) dendrimers for the potential cellular delivery of antisense oligonucleotides targeting the epidermal growth factor receptor. Pharm. Res. 21(30), 458-466 (2004).

71 Hollins AJ, Omidi Y, Benter IF, Akhtar S. Toxicogenomics of drug delivery systems: exploiting delivery system-induced changes in target gene expression to enhance siRNA potency. J. Drug Target. 15(1), 83-88 (2007).

- Indicates that toxicity of siRNA nanocarriers can occur in a subtle manner by altering gene expression.

72 Felgner PL, Gadek TR, Holm M et al. Lipofection: a highly efficient, lipid-mediated DNA-transfection procedure. Proc. Natl Acad. Sci. USA 84(21), 7413-7417 (1987).

73 Simberg D, Weisman S, Talmon Y, Barenholz Y. DOTAP (and other cationic lipids): 
chemistry, biophysics, and transfection. Crit. Rev. Ther. Drug Carrier Syst. 21(4), 257-317 (2004).

74 Haque ME, McIntosh TJ, Lentz BR. Influence of lipid composition on physical properties and PEG-mediated fusion of curved and uncurved model membrane vesicles: 'nature's own' fusogenic lipid bilayer. Biochemistry 40(14), 4340-4348 (2001).

75 Nchinda G, Überla K, Zschörnig O. Characterization of cationic lipid DNA transfection complexes differing in susceptibility to serum inhibition. $B M C$ Biotechnol. 2, 12 (2002).

76 Lappalainen K, Jaaskelainen I, Syrjanen K, Urtti A, Syrjänen S. Comparison of cell proliferation and toxicity assays using two cationic liposomes. Pharm. Res. 11, 1127-1131 (1994).

77 Aberle AM, Tablin F, Zhu J, Walker NJ, Gruenert DC, Nantz MH. A novel tetraester construct that reduces cationic lipid-associated cytotoxicity. Implications for the onset of cytotoxicity. Biochemistry 37 , 6533-6540 (1998).

78 Bottega R, Epand RM. Inhibition of protein kinase $\mathrm{C}$ by cationic amphiphiles. Biochemistry 31, 9025-9030 (1992).

79 Freedland SJ, Malone RW, Borchers HM et al. Toxicity of cationic lipid-ribozyme complexes in human prostate tumor cells can mimic ribozyme activity. Biochem. Mol. Med. 59, 144-153 (1996).

80 Omidi Y, Hollins AJ, Benboubetra M, Drayton R, Benter IF, Akhtar S. Toxicogenomics of non-viral vectors for gene therapy: a microarray study of Lipofectin- and oligofectamine-induced gene expression changes in human epithelial cells. J. Drug Target. 11(6), 1-13 (2003).

81 Tousignant JD, Gates AL, Ingram LA et al. Comprehensive analysis of the acute toxicities induced by systemic administration of cationic lipid:plasmid DNA complexes in mice. Hum. Gene Ther. 11, 2493-2513 (2000).

82 Zhang J-S, Liu F, Huang L. Implications of pharmacokinetic behavior of lipoplex for its inflammatory toxicity. Adv. Drug Deliv. Rev. 57, 689-698 (2005).

83 Zimmermann TS, Lee AC, Akinc A et al. RNAi-mediated gene silencing in non-human primates. Nature 441(7089), 111-114 (2006).

84 Tabernero J, Shapiro GI, LoRusso PM et al. First-in-humans trial of an RNA interference therapeutic targeting VEGF and KSP in cancer patients with liver involvement. Cancer Discov. 3(4), 406-417 (2013).

85 Ramanathan RK, Hamburg SI, Borad MJ et al. A Phase 1 dose escalation study of TKM-080301, a RNAi therapeutic directed against PLK1, in patients with advanced solid tumors. Presented at: AACR 2013 Annual Meeting, Washington, DC, USA, 6-10 April 2013.

86 Ojea-Jiménez I, Comenge J, García-Fernández $\mathrm{L}$ et al. Engineered inorganic nanoparticles for drug delivery applications. Curr. Drug Metab. 14(5), 518-523 (2013).

87 Gautier J, Allard-Vannier E, Munnier E, Soucé M, Chourpa I. Recent advances in theranostic nanocarriers of doxorubicin based on iron oxide and gold nanoparticles. J. Control. Release 169(1-2), 48-61 (2013).

88 Guo S, Huang Y, Jiang Q et al. Enhanced gene delivery and siRNA silencing by gold nanoparticles coated with charge-reversal polyelectrolyte. ACS Nano 4(9), 5505-5511 (2010).

89 Chen YS, Hung YC, Liau I, Huang GS. Assessment of the in vivo toxicity of gold nanoparticles. Nanoscale Res. Lett. 4(8), 858-864 (2009).

90 Taratula O, Garbuzenko O, Savla R, Wang YA, He H, Minko T. Multifunctional nanomedicine platform for cancer specific delivery of siRNA by superparamagnetic iron oxide nanoparticles-dendrimer complexes. Curr. Drug Deliv. 8(1), 59-69 (2011).

91 Jiang S, Eltoukhy AA, Love KT, Langer R, Anderson DG. Lipidoid-coated iron oxide nanoparticles for efficient DNA and siRNA delivery. Nano Lett. 13(3), 1059-1064 (2013).

92 Tassa C, Shaw SY, Weissleder R. Dextrancoated iron oxide nanoparticles: a versatile platform for targeted molecular imaging, molecular diagnostics, and therapy. Acc. Chem. Res. 44(10), 842-852 (2011).

93 Namiki Y, Namiki T, Yoshida H et al. A novel magnetic crystal-lipid nanostructure for magnetically guided in vivo gene delivery. Nat. Nanotechnol. 4(9), 598-606 (2009).

94 Iijima S. Helical microtubules of graphitic carbon. Nature 354, 56-58 (1991).

95 Varkouhi AK, Foillard S, Lammers T et al. siRNA delivery with functionalized carbon nanotubes. Int. J. Pharm. 416(2), 419-425 (2011).

96 van der Zande M, Junker R, Walboomers XF, Jansen JA. Carbon nanotubes in animal models: a systematic review on toxic potential. Tissue Eng. Part B Rev. 17, 57-69 (2011).

97 Poland CA, Duffin R, Kinloch I et al. Carbon nanotubes introduced into the abdominal cavity of mice show asbestos-like pathogenicity in a pilot study. Nat. Nanotechnol. 3(7), 423-428 (2008).

98 Palomaki J, Valimaki E, Sund J et al. Long, needle-like carbon nanotubes and asbestos activate the NLRP3 inflammasome through a similar mechanism. ACS Nano 5(9), 6861-6870 (2011).

99 Kovtun A, Heumann R, Epple M. Calcium phosphate nanoparticles for the transfection of cells. Biomed. Mater. Eng. 19(2-3), 241-247 (2009)

100 Giger EV, Castagner B, Räikkönen J, Mönkkönen J, Leroux JC. siRNA transfection with calcium phosphate nanoparticles stabilized with PEGylated chelators. $A d v$. Healthc. Mater. 2(1), 134-144 (2013).

101 Bonnet ME, Erbacher P, Bolcato-Bellemin AL. Systemic delivery of DNA or siRNA mediated by linear polyethylenimine (L-PEI) does not induce an inflammatory response. Pharm. Res. 25, 2972-2982 (2008).

102 Swami A, Kurupati RK, Pathak A, Singh Y, Kumar P, Gupta KC. A unique and highly efficient non-viral DNA/siRNA delivery system based on PEI-bisepoxide nanoparticles. Biochem. Biophys. Res. Commun. 362(4), 835-841 (2007).

- Describes a systematic approach to screen for nanomaterials with the optimal efficacy-toxicity balance.

103 Swami A, Goyal R, Tripathi SK et al. Effect of homobifunctional crosslinkers on nucleic acids delivery ability of PEI nanoparticles. Int. J. Pharm. 374(1-2), 125-138 (2009).

104 Breunig M, Lungwitz U, Liebl R, Goepferich A. Breaking up the correlation between efficacy and toxicity for nonviral gene delivery. Proc. Natl Acad. Sci. USA 104, 14454-14459 (2007).

105 Lin C, Blaauboer CJ, Timoneda MM et al. Bioreducible poly(amido amine)s with oligoamine side chains: synthesis, characterization, and structural effects on gene delivery. J Control. Release 126, 166-174 (2008).

106 Beyerle A, Braun A, Banerjee A et al. Inflammatory responses to pulmonary application of PEI-based siRNA nanocarriers in mice. Biomaterials 32(33), 8694-8701 (2011).

107 Zheng D, Giljohann DA, Chen DL et al. Topical delivery of siRNA-based spherical nucleic acid nanoparticle conjugates for gene regulation. Proc. Natl Acad. Sci. USA 109(30), 11975-11980 (2012).

108 Love KT, Mahon KP, Levins CG et al. Lipid-like materials for low-dose, in vivo gene silencing. Proc. Natl Acad. Sci. USA 107(5), 1864-1869 (2010).

109 Muller RH, Ruhl D, Runge S, SchulzeForster K, Mehnert W. Cytotoxicity of solid lipid nanoparticles as a function of the lipid matrix and the surfactant. Pharm. Res. 14, 458-462 (1997). 
110 Xue HY, Narvikar M, Zhao JB, Wong HL. Lipid encapsulation of cationic polymers in hybrid nanocarriers reduces their non-specific toxicity to breast epithelial cells. Pharm. Res. 30(2), 572-583 (2013).

- Demonstrates the use of a hybrid approach to reduce the toxicity of cationic polymers.

111 Masotti A, Moretti F, Mancini F et al. Physicochemical and biological study of selected hydrophobic polyethylenimine-based polycationic liposomes and their complexes with DNA. Bioorgan. Med. Chem. 15, 1504-1515 (2007).

112 Elbakry A, Wurster EC, Zaky A et al. Layer-by-layer coated gold nanoparticles: size-dependent delivery of DNA into cells. Small 8(24), 3847-3856 (2012).

113 Greish K. Enhanced permeability and retention (EPR) effect for anticancer nanomedicine drug targeting. Methods Mol. Biol. 624, 25-37 (2010).

114 Mokhtarieh AA, Cheong S, Kim S, Chung BH, Lee MK. Asymmetric liposome particles with highly efficient encapsulation of siRNA and without nonspecific cell penetration suitable for target-specific delivery. Biochim. Biophys. Acta. 1818(7), 1633-1641 (2012).

115 Jiang HL, Xu CX, Kim YK et al. The suppression of lung tumorigenesis by aerosol-delivered folate-chitosan-graft polyethylenimine/Akt1 shRNA complexes through the Akt signaling pathway. Biomaterials 30(29), 5844-5852 (2009).

116 Malhotra M, Tomaro-Duchesneau C, Saha $S$ et al. Development and characterization of chitosan-PEG-TAT nanoparticles for the intracellular delivery of siRNA. Int. J. Nanomedicine 8, 2041-2052 (2013).

117 Greish K, Thiagarajan G, Ghandehari H. In vivo methods of nanotoxicology. Methods Mol. Biol. 926, 235-253 (2012).

- Outlines the commonly used methods to evaluate in vivo nanotoxicology.

118 Arora S, Rajwade JM, Paknikar KM. Nanotoxicology and in vitro studies: the need of the hour. Toxicol. Appl. Pharmacol. 258(2), 151-165 (2012).

\section{Websites}

201 Nobelprize.org. The Nobel Prize in Physiology or Medicine 2006 - Andrew Z. Fire, Craig C Mello. www.nobelprize.org/nobel_prizes/medicine/ laureates/2006/advanced.html (Accessed on 1 July 2013)
202 ClinicalTrials.gov. Tolerance and Effect on Intraocular Pressure After Administration of SYL040012.

http://clinicaltrials.gov/ct2/show/results/ NCT00990743

(Accessed 1 July 2013)

203 ClinicalTrials.gov. Intranasal ALN-RSV01 administered to adult volunteers experimentally inoculated with respiratory syncytial virus. http://clinicaltrials.gov/ct2/show/NCT004968 21 ?term=nct $00496821 \&$ rank=1 (Accessed 1 July 2013)

204 Tekmira Pharmaceuticals. Tekmira Pharmaceuticals completes ApoB SNALP Phase 1 clinical trial (Posted 7 January 2010).

http://investor.tekmirapharm.com/ releasedetail.cfm?releaseid $=534353$ (Accessed 20 June 2013)

205 Frederick National Lab - Nanotechnology characterization laboratory. Assay cascade protocols. http://ncl.cancer.gov/working_assay-cascade. asp (Accessed 4 July 2013)

- Provides a detailed list of in vitro assays for nanotoxicity evaluation. 